\title{
Figures, tables, boxes and case studies
}

Figures

6.I Interactivity and interaction seen as dimensions of public engagement projects

7.I Typology of social media

\section{Tables}

7.I Guides to working with the media

8.I International definitions of public/citizen engagement and participation

8.2 Problems in evidence-based policymaking

9.I Key planning steps for citizen science projects

\section{Boxes}

3.I Segmentation models

3.2 Determining a segment is workable

3.3 Identity-related categories for cultural institutions

3.4 Determining the target segment

4.I Virtual museum and gallery examples

4.2 Tips for preparing for face-to-face presentation

4.3 Tips for dealing with nerves in face-to-face presentation

4.4 Managing conflict and controversy in face-to-face communication

5.I Example projects bringing artists and researchers together

5.2 Practical tips on collaborative working

6.I Digital story examples 
7.I Ten tips on writing for popular publications $\quad$ I35

\begin{tabular}{ll}
7.2 & Pitching to editors \\
\hline
\end{tabular}

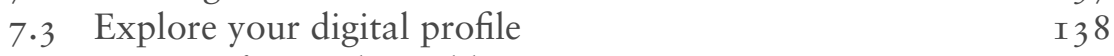

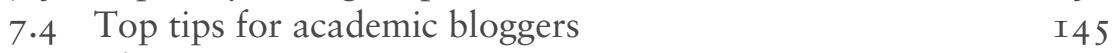

$\begin{array}{rr}7.5 \text { Altmetrics } & \text { I } 58\end{array}$

8.I Resources providing guidance on public engagement $\quad$ I 70

8.2 Tips for designing engagement I7I

8.3 Tips for communicating with policymakers $\quad$ I84

IO.I Resources for designing aims, questions and objectives 2 I 2

I0.2 Unusual public engagement outputs 2 I 5

I0.3 Selected frameworks and guidance for evaluation design 222

$\begin{array}{ll}\text { I0.4 Free online analysis programmes } & 225\end{array}$

$\begin{array}{lll}\text { II.I International ethical codes and guidelines } & 247\end{array}$

I2.I Making reports user friendly and accessible 259

$\begin{array}{ll}\text { I2.2 Evaluation archives and databases } & \mathbf{2 6 0}\end{array}$

I2.3 Research communication conferences 262

I2.4 Selected academic journals of relevance to research
communication

\section{Case studies}

4.I Brain Day, Centre for Brain Research, University of Auckland

4.2 Connected Communities Public Dialogue Day

5.I Look At Me! Engaging older women with research

5.2 Arts@CERN 99

6.I Sticky, animation and science communication II9

6.2 Virtual Romans - merging technology and archaeology I25

7.I Garnering blog readership I46

7.2 Second Life: Science Circle I 56

8. I The People's Campaign for Decentralised Planning I62

8.2 Science for Environment Policy $\quad$ I82

9.I Citizen journalists contributing to public health I90

9.2 Public Lab: supporting communities to tackle environmental concerns $\quad$ I95

IO.I The Centre for Appearance Research and Dove Self-Esteem $\begin{array}{ll}\text { Project } & 209\end{array}$

I0.2 The Thrill Engineer $23 \mathrm{I}$

II.I Ethically impossible $\quad 239$

$\begin{array}{ll}\text { II.2 Ethics and older people } & 244\end{array}$ 